Arq. Bras. Med. Vet. Zootec., v.56, n.2, p.242-250, 2004

\title{
Variabilidade genética e limite da seleção em populações de diferentes tipos de acasalamento
}

[Genetic variability and selection limit in populations of different mating designs]

\author{
E.E. Cunha ${ }^{1}$, R.F. Euclydes ${ }^{2}$, R.A. Torres ${ }^{2}$, P.S. Lopes $^{2}$, J.I. Ribeiro Júnior ${ }^{2}$, P.C.S. Carneiro ${ }^{2}$ \\ ${ }^{1}$ Estudante de Doutorado da Universidade Federal de Viçosa \\ Av. P.H. Rolfs, s/n \\ 36571-000 - Viçosa, MG \\ ${ }^{2}$ Universidade Federal de Viçosa
}

\begin{abstract}
RESUMO
Populações de cinco diferentes tipos de acasalamento, submetidas à seleção baseada no melhor preditor linear não-viesado (BLUP), foram avaliadas quanto às perdas genéticas por fixação de alelos desfavoráveis e limite da seleção, durante 50 gerações. Foram utilizados dados simulados na obtenção do genoma dos indivíduos de todas as populações. Uma característica quantitativa de herdabilidade 0,10 foi estudada em populações de seleção, com a seguinte estrutura de dados: razão sexual de 10, 20, 25 e 50 e tamanho efetivo da população de 36,36, 19,05, 15,38, e 7,84, respectivamente. Para cada razão sexual, formaram-se populações correspondentes aos tipos de acasalamento efetuados entre os reprodutores, em todas as gerações: acasalamentos preferenciais entre meios-irmãos e irmãos completos, acasalamentos preferenciais entre meios-irmãos, acasalamentos ao acaso, exclusão de acasalamentos entre irmãos completos e exclusão de acasalamentos entre meios-irmãos e irmãos completos. Valores percentuais mais baixos para locos fixados desfavoravelmente e limite da seleção mais alto foram observados na menor razão sexual $(\mathrm{d}=10)$, na qual houve também melhor distinção entre os tipos de acasalamento estudados.
\end{abstract}

Palavras-chave: perda genética, alelo desfavorável, razão sexual, limite da seleção, tamanho efetivo

\begin{abstract}
Populations of five different mating designs, submitted to selection based on best linear unbiased predicto $(B L U P) r$, were evaluated regarding to genetic losses by fixation of unfavorable alleles and selection limit, during 50 generations. Simulated data were used to obtain the genome of all individuals of the populations. A quantitative trait with heritability of 0.10 was studied in the selected populations, with the following structure: sexual ratio of 10, 20, 25, and 50 and effective population size of 36.36, 19.05, 15.38 and 7.84 , respectively. For each sexual ratio different populations were generated corresponding to the following mating designs: preferential matings between half and full sibs, preferential matings between half sibs, random matings, exclusion of matings between full sibs and exclusion of matings of half and full sibs. Smallest percentage of unfavorably fixed loci and the highest selection limit were observed in the lower sexual ratio $(d=10)$. Better differentiation between the studied mating designs was also observed for the lower sexual ratio.
\end{abstract}

Keywords: genetic loss, unfavorable allele, sexual ratio, selection limit, effective size

Apoio financeiro: $\mathrm{CNPq}$

Recebido para publicação em 12 de dezembro de 2002

Recebido para publicação, após modificações, em 29 de setembro de 2003

E-mail: eliz.cunha@bol.com.br 


\section{INTRODUÇÃO}

A seleção artificial implica progresso genético, mas também contribui para aumentar os níveis de consangüinidade na população. Isso resulta em depressão por consangüinidade na própria característica considerada na seleção e, ainda, nos componentes de adaptação, tendo importante efeito sobre a resposta à seleção, a médio e longo prazos, principalmente considerando-se a redução na probabilidade de fixar genes favoráveis.

Falconer (1987) afirmou que muitas características de produção, como a taxa de crescimento e a eficiência alimentar, não apresentam alto grau de depressão por consangüinidade, tornando a depressão um fator não tão importante para esses tipos de característica. Meuwissen e Woolliams (1994) ressaltaram que a adaptação, definida como uma combinação de características de fertilidade e viabilidade - geralmente não submetida à seleção direta em razão de sua baixa herdabilidade, apesar de reconhecida importância econômica - é influenciada pela depressão por consangüinidade. Assim, pelo menos no médio prazo, a restrição mais rigorosa ao aumento da consangüinidade seria imposta pela depressão por consangüinidade na adaptação. Segundo Falconer (1987), estudos com diferentes espécies de animais têm mostrado efeitos prejudiciais, detectáveis em nível de $10 \%$ de consangüinidade, sobre as características do valor adaptativo.

Caballero (1994), Sanchez et al. (1999) e Bijma e Woolliams (2000) comentaram o fato, não menos relevante, de a seleção artificial acarretar decréscimos no tamanho efetivo da população. Essa redução no tamanho efetivo pode ter considerável importância na conservação genética das populações de pequenos núcleos ou daquelas submetidas a alta intensidade de seleção, bem como nos casos de seleção baseada em valores genéticos, obtidos por meio de índices e do BLUP, utilizando-se o modelo animal.

Segundo Nicholas e Smith (1983), os avanços recentes envolvendo o uso de técnicas de ovulação múltipla e transferência de embrião em bovinos e ovinos e o uso apenas da informação do ancestral nas avaliações genéticas, a fím de encurtar o intervalo de gerações, são alguns aspectos que tendem a acelerar a perda de variabilidade genética na população selecionada. Dessa forma, a redução na probabilidade de fixar genes favoráveis diminuiria a resposta genética à seleção, a médio e longo prazos. Keller et al. (1990), ao investigarem a importância de fatores que afetam a resposta à seleção numa população fechada, inferiram que a depressão por consangüinidade poderia ser o principal fator na redução da resposta genética à seleção.

A consangüinidade pode ser definida como um sistema de acasalamento em que indivíduos mais aparentados entre si do que a média da população são escolhidos para pais da próxima geração, contribuindo para aumentar o nível de homozigose. Shimbo et al. (2000) enfatizaram que os acasalamentos entre parentes podem acontecer por diversas razões, como por exemplo, nos casos em que os criadores pretendem que os animais escolhidos transmitam suas características raciais a seus descendentes, de forma mais intensa (prepotência) ou, então, em populações pequenas, em que as opções de acasalamentos são reduzidas e não há como evitar os acasalamentos entre aparentados.

Na literatura (Toro et al., 1988; Woolliams, 1989; Toro, Perez-Enciso, 1990; Santiago, Caballero, 1995; Meuwissen, 1997) há relatos de alguns tipos de estratégias envolvendo esquemas de acasalamentos direcionados entre os reprodutores escolhidos, a fim de amenizar os efeitos prejudiciais da consangüinidade.

De acordo com Bijma e Woolliams (2000), ter uma idéia a respeito da taxa de consangüinidade numa população é tão importante quanto conhecer a resposta genética esperada, a partir da aplicação de um determinado método de seleção. Nesse sentido, a preocupação com o aumento nos níveis de consangüinidade tem motivado a realização de inúmeros trabalhos, abordando a escolha de estratégias de seleção mais apropriadas, incluindo métodos de seleção e tipos de acasalamento, considerando-se os efeitos negativos da depressão por consangüinidade.

Este estudo foi conduzido para avaliar a variabilidade genética e o limite da seleção em populações com diferentes valores de tamanho efetivo, selecionadas com base no BLUP, e submetidas a cinco tipos de acasalamento. 


\section{MATERIAL E MÉTODOS}

Na simulação dos dados, utilizou-se o programa GENESYS (Euclydes, 1996), elaborado para o compilador FORTRAN. O genoma simulado constituiu-se de 250 locos quantitativos dialélicos distribuídos ao acaso, em 20 pares de cromossomos autossômicos de tamanhos aleatórios, cujo comprimento total foi de 4.000 centimorgans. As freqüências iniciais simuladas para os locos quantitativos apresentaram distribuição uniforme e valor inicial médio de 0,50. As freqüências gênicas iniciais foram iguais em ambos os sexos. Os efeitos aditivos dos genes seguiram a distribuição normal e não houve interações do tipo não-aditivas entre eles. Além do efeito fixo de sexo, foi admitido um efeito fixo (qualquer) com 10 classes.

Foi simulada uma população-base constituída de 1.000 indivíduos, 500 machos e 500 fêmeas, que permitiu o estudo de uma característica quantitativa de herdabilidade igual a 0,10. Considerou-se que o parentesco entre os indivíduos dessa população era nulo.

A partir da população-base, foi simulada uma população inicial, na qual foram escolhidos e acasalados ao acaso, 10 machos e 100 fêmeas, gerando oito descendentes por casal. Com essa população inicial, foram obtidas as populações de seleção por meio do melhor preditor linear não-viesado (BLUP), utilizando as equações de modelos mistos, com uso do modelo animal. Foram considerados os efeitos fixos de sexo e de 10 classes, bem como os aleatórios de animal e ambiente.

O processo de seleção ocorreu durante 50 gerações consecutivas e discretas, com 20 repetições por geração, a fim de reduzir os efeitos da flutuação gênica.

As populações selecionadas tiveram tamanho real de 600 indivíduos por geração, correspondendo a seis filhos por casal. Foram avaliados os valores $10,20,25$ e 50 de razão sexual d (número de fêmeas/número de machos), correspondendo a $10,5,4$ e 2 machos, respectivamente, selecionados por geração, acasalados sempre com 100 fêmeas. Assim, o tamanho efetivo $(\mathrm{Ne})$ de cada população foi calculado, segundo fórmula proposta por Wright (1931), citada por Falconer (1987), $\frac{1}{N_{e}}=\frac{1}{4 N_{m}}+\frac{1}{4 N_{f}}$, obtendo-se os seguintes valores de Ne: 36,36, 19,05, 15,38 e 7,84, seqüencialmente. A estes valores, corresponderam os seguintes níveis de intensidade de seleção aplicada aos machos: $2,23,2,49,2,56$ e 2,82, nessa ordem. A intensidade de seleção para fêmeas foi de 1,091, em todas as populações.

Em cada valor de razão sexual estudada, o número de populações sob seleção correspondeu ao total de tipos de acasalamento entre os reprodutores escolhidos para pais da geração seguinte: acasalamentos preferenciais de meiosirmãos e irmãos completos (uso de MI e IC), acasalamentos preferenciais entre meios-irmãos (uso de MI), acasalamentos ao acaso (ao acaso), exclusão de acasalamentos entre irmãos completos (exclusão de IC) e exclusão de acasalamentos de meios-irmãos e irmãos completos (exclusão de MI e IC).

Foram avaliadas as perdas genéticas em percentagem, atribuídas à fixação de alelos desfavoráveis, e o limite da seleção.

\section{RESULTADOS E DISCUSSÃO}

Nas Fig. 1, 2, 3 e 4 são apresentados os valores percentuais de perdas por fixação de alelos desfavoráveis, nos diferentes tipos de acasalamento, utilizando a metodologia BLUP de seleção, considerando os valores da razão sexual $\mathrm{d}$, de $10,20,25$ e 50 , respectivamente. Os aumentos crescentes nas taxas de perdas por fixação ao longo das gerações de seleção podem ser atribuídos à fixação de alelos em locos quantitativos desfavoráveis, que tem como conseqüência, a redução da variabilidade genética presente nessas populações. 


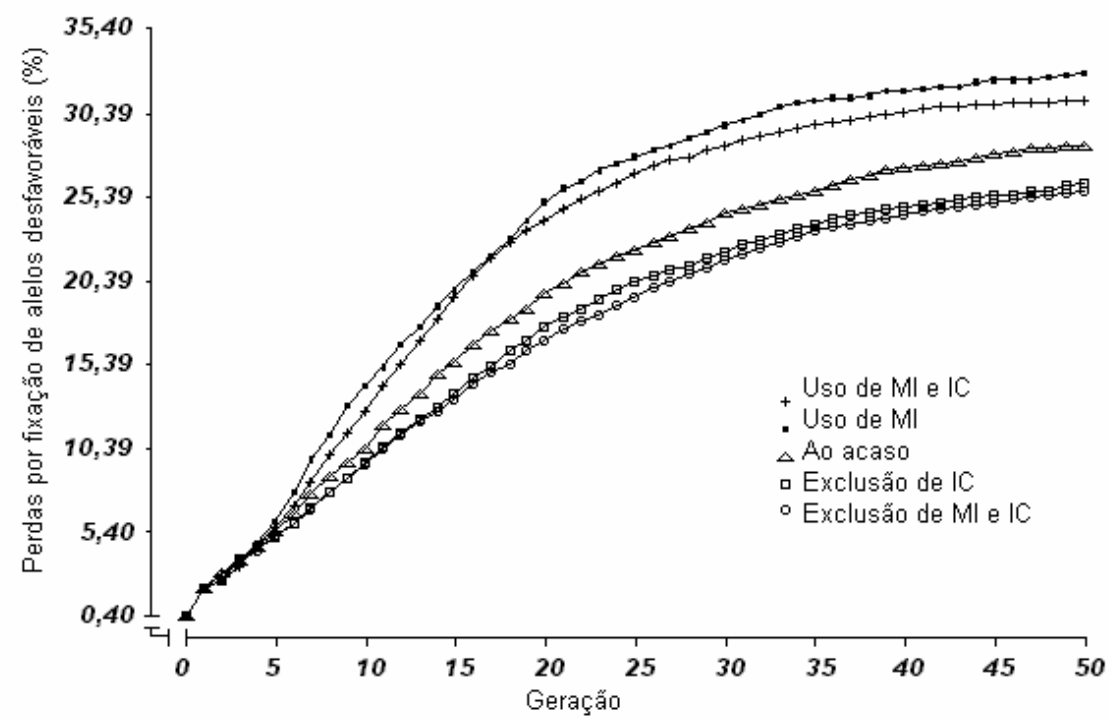

Figura 1. Valores, em percentagem, das perdas por fixação de alelos desfavoráveis obtidos nos diferentes tipos de acasalamento com razão sexual 10 e seleção baseada no BLUP, ao longo de 50 gerações (MI= meios-irmãos; $\mathrm{IC}=$ irmãos completos).

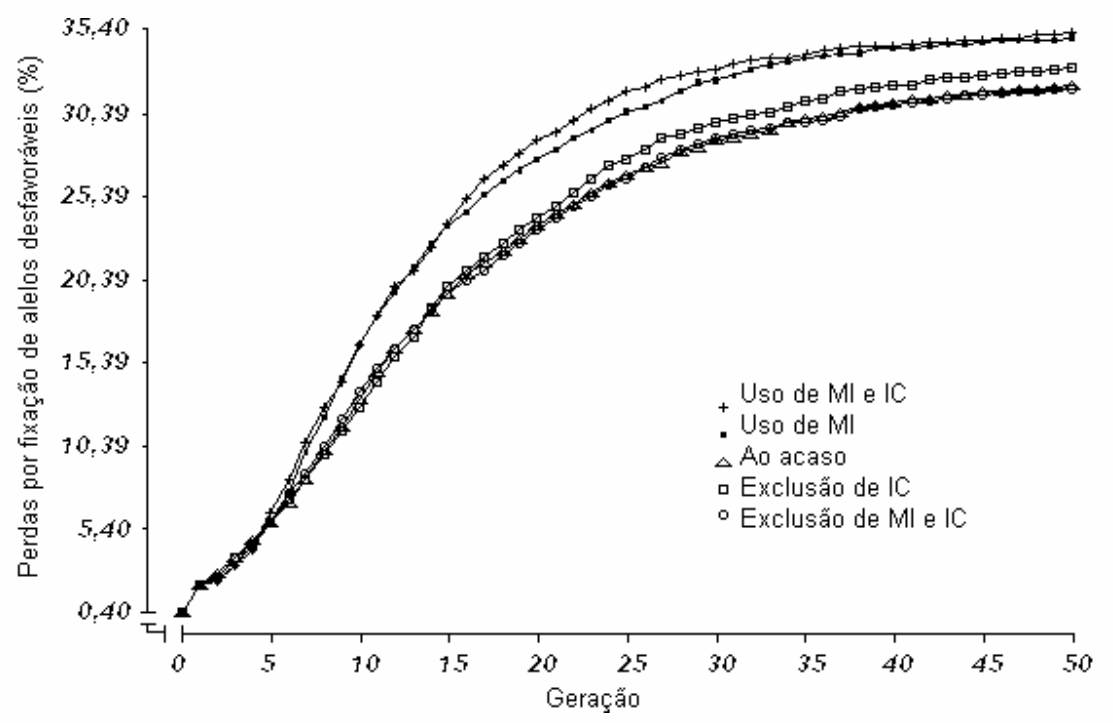

Figura 2. Valores, em percentagem, das perdas por fixação de alelos desfavoráveis obtidos nos diferentes tipos de acasalamento com razão sexual 20 e seleção baseada no BLUP, ao longo de 50 gerações (MI= meios-irmãos; IC= irmãos completos). 


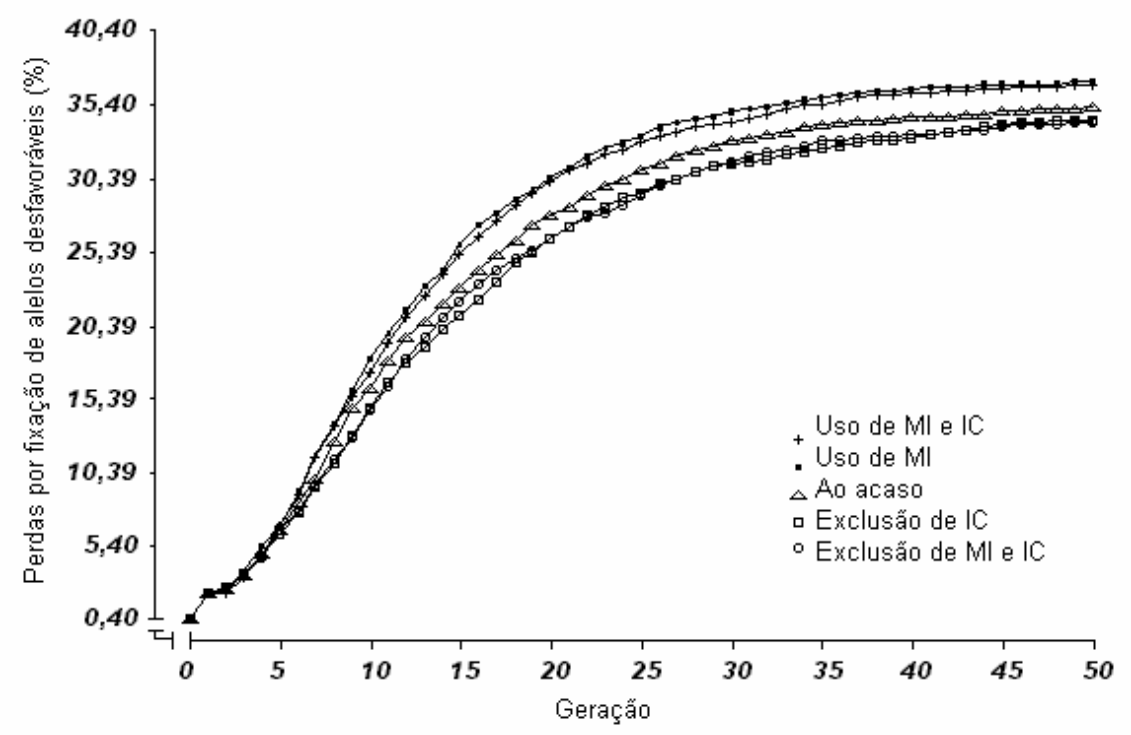

Figura 3. Valores, em percentagem, das perdas por fixação de alelos desfavoráveis obtidos nos diferentes tipos de acasalamento com razão sexual 25 e seleção baseada no BLUP, ao longo de 50 gerações (MI= meios-irmãos; IC= irmãos completos).

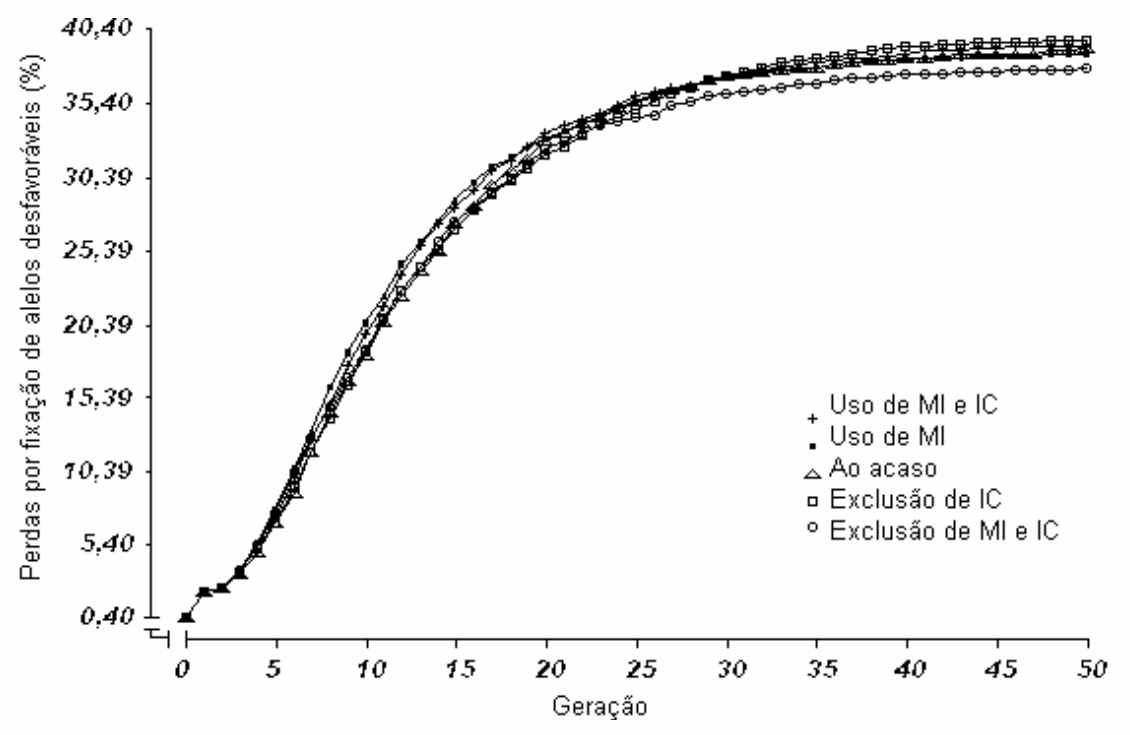

Figura 4. Valores, em percentagem, das perdas por fixação de alelos desfavoráveis obtidos nos diferentes tipos de acasalamento com razão sexual 50 e seleção baseada no BLUP, ao longo de 50 gerações (MI= meios-irmãos; IC= irmãos completos). 
De modo geral, as perdas por fixação mostraramse maiores nos tipos de acasalamento preferenciais de irmãos, conforme esperado, uma vez que acasalamentos entre indivíduos aparentados contribuem para o aumento nos níveis de consangüinidade, decorrente do aumento na homozigose e, conseqüentemente, na probabilidade de ocorrência de alelos desfavoráveis para um mesmo gene.

Em relação ao valor da razão sexual, observa-se que, à medida que ele aumentou, houve aumento também na aceleração da taxa de perdas por fixação, em todos os tipos de acasalamento, no decorrer das gerações. Maior razão sexual pressupõe elevação no nível de consangüinidade e, pela mesma razão acima, na probabilidade de ocorrência de alelos desfavoráveis, uma vez que nesses casos, um único macho estaria sendo utilizado para reprodução com várias fêmeas, aumentando o tamanho das famílias de irmãos. Nesse sentido, na menor razão sexual $(d=10)$ (Fig. 1), foram observados uma separação maior entre os tipos de acasalamento e um menor percentual de perda por fixação, em cada tipo de acasalamento estudado, ao longo das gerações.

Em animais domésticos, existe sempre a preocupação, por parte dos criadores, em evitar acasalamentos entre indivíduos aparentados, em função dos temidos efeitos prejudiciais da consangüinidade, principalmente sobre aquelas características de baixa herdabilidade, ligadas à adaptação e reprodução. Diante dos resultados obtidos neste estudo, percebeu-se que mesmo evitando esses tipos de acasalamento, sobretudo aqueles entre irmãos, ainda assim, os níveis de homozigose numa população sob seleção tenderam a aumentar em decorrência do esgotamento da variância genética aditiva, ou seja, pela fixação de alelos favoráveis e desfavoráveis e, ainda, pela ocorrência do efeito Bulmer.

Falconer (1987) ressaltou que, teoricamente, a consangüinidade tende a fazer com que haja fixação de alelos desfavoráveis em alguns locos, de tal forma que é esperada uma redução na resposta total e na duração da resposta à seleção, caso ela seja praticada numa pequena população submetida a alta taxa de consangüinidade.

Merece ser comentado o fato de a seleção neste estudo basear-se no BLUP, metodologia muito eficiente na obtenção de ganho genético em curto prazo, mas que se utiliza das informações de parentes na seleção do indivíduo e que, portanto, contribui para a elevação nos níveis de consangüinidade. Euclydes (1996), ao trabalhar com simulação, afirmou que, aparentemente, o BLUP é capaz de localizar indivíduos portadores de locos quantitativos "importantes" e fixá-los nos alelos favoráveis. Entretanto, durante a fixação de alelos de maior valor fenotípico, ocorrem perdas, ou seja, fixação de locos de menor importância nos alelos desfavoráveis, mas que juntos, possuem grande valor. Esse acontecimento parece estar bastante associado à consangüinidade.

Belonsky e Kenedy (1988), citados por Euclydes (1996), afirmaram que o fato de a seleção baseada no BLUP atribuir maior importância às informações da família, sobretudo quando se consideram características de baixa herdabilidade $\left(\mathrm{h}^{2}=0,10\right)$, aumenta ainda mais o grau de homozigose, acentuando assim as perdas genéticas.

Outro fator muito importante ao se estudarem os processos de seleção é o tempo em que a população exibe resposta a essa mesma seleção, em função da variabilidade genética nela existente. De acordo com Falconer (1987), os efeitos da consangüinidade durante a seleção têm sido ignorados nos estudos sobre seus limites.

Nas Fig. 5, 6, 7 e 8, correspondentes aos níveis de razão sexual d de $10,20,25$ e 50, nessa ordem, com respeito ao limite da seleção, foram observados aumentos mais acentuados na taxa de seu decréscimo, no decorrer das 50 gerações de seleção, proporcionalmente ao aumento na razão sexual. Dessa forma, na razão sexual d igual a 50 (Fig. 8), o limite da seleção exibiu os mais baixos valores, após as cinco primeiras gerações de seleção. 


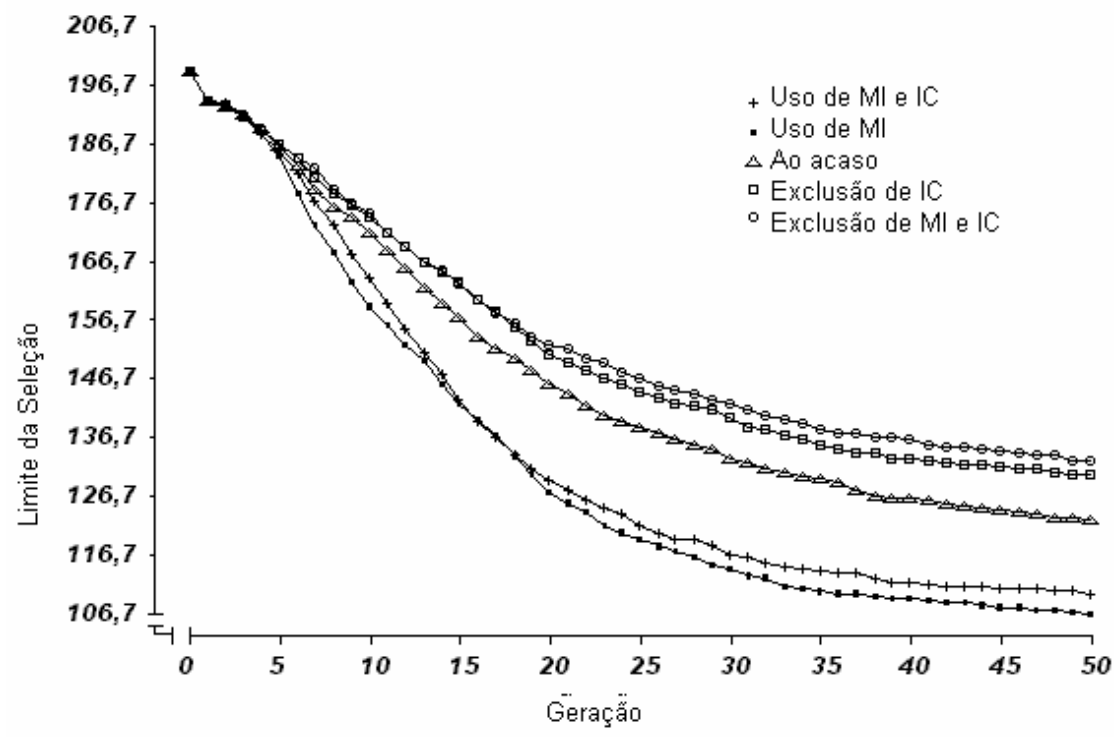

Figura 5. Valores do limite da seleção obtidos nos diferentes tipos de acasalamento com razão sexual 10 e seleção baseada no BLUP, ao longo de 50 gerações ( $\mathrm{MI}=$ meios-irmãos; $\mathrm{IC}=$ irmãos completos).

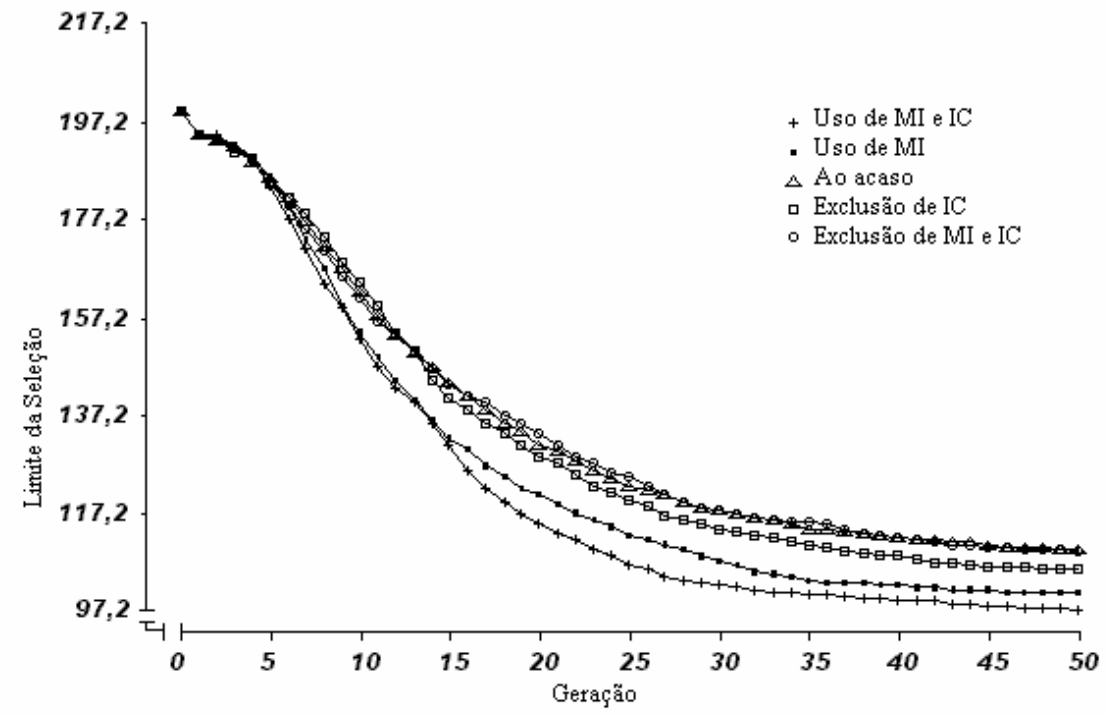

Figura 6. Valores do limite da seleção obtidos nos diferentes tipos de acasalamento com razão sexual 20 e seleção baseada no BLUP, ao longo de 50 gerações $(\mathrm{MI}=$ meios-irmãos; $\mathrm{IC}=$ irmãos completos). 


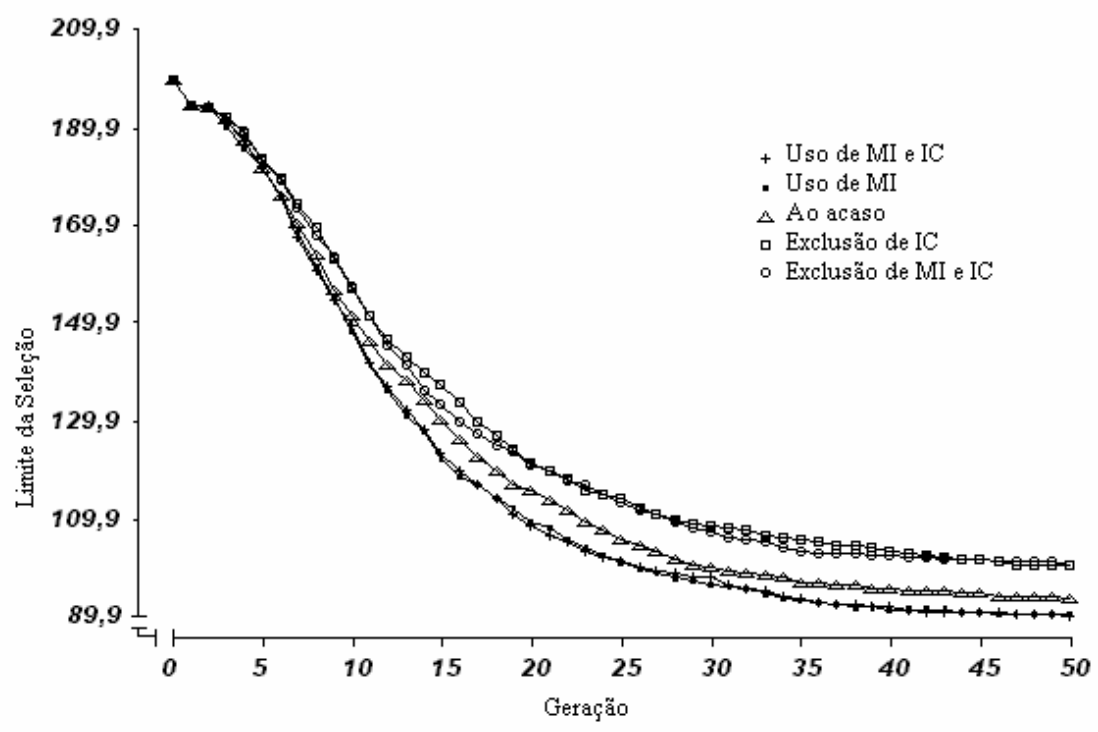

Figura 7. Valores do limite da seleção obtidos nos diferentes tipos de acasalamento com razão sexual 25 e seleção baseada no BLUP, ao longo de 50 gerações ( $\mathrm{MI}=$ meios-irmãos; $\mathrm{IC}=$ irmãos completos).

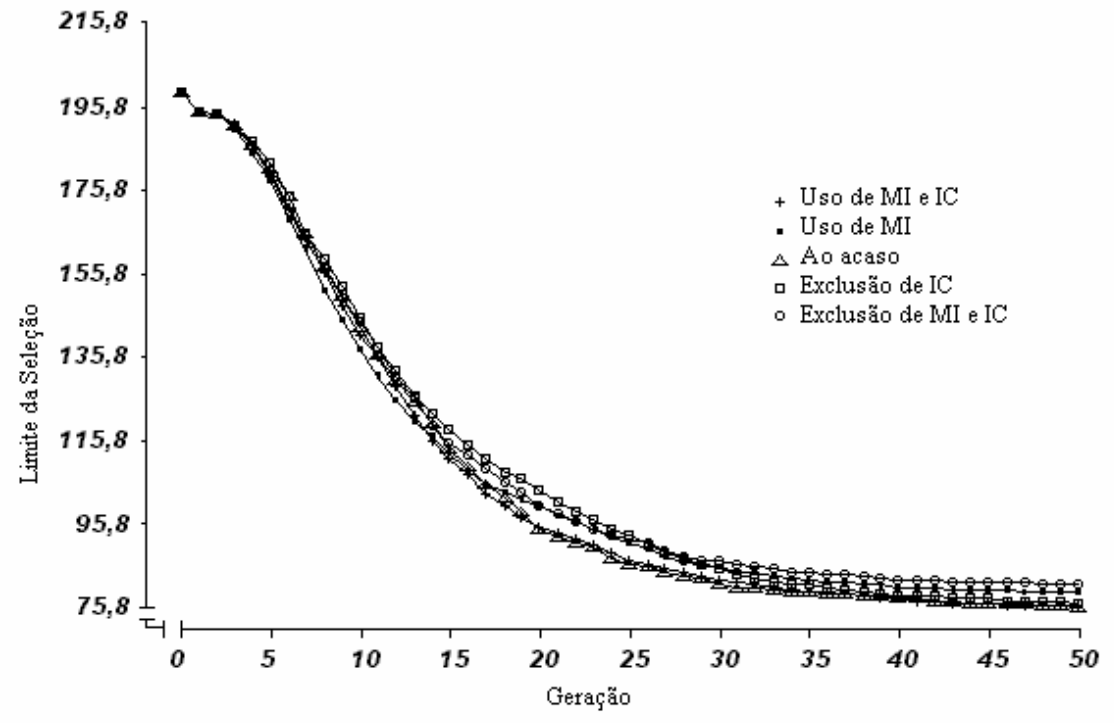

Figura 8. Valores do limite da seleção obtidos nos diferentes tipos de acasalamento com razão sexual 50 e seleção baseada no BLUP, ao longo de 50 gerações ( $\mathrm{MI}=$ meios-irmãos; $\mathrm{IC}=$ irmãos completos).

Com relação aos tipos de acasalamento estudados em cada valor da razão sexual, fica evidente que as maiores diferenças entre eles ocorreram no menor valor da razão sexual $(\mathrm{d}=$ 10). Assim, os valores do limite da seleção foram menores para os tipos de acasalamento 
preferenciais de irmãos e maiores para os tipos que excluíram acasalamentos entre irmãos, conforme esperado. Contudo, à medida que a razão sexual aumentava, os diferentes tipos tenderam a apresentar comportamentos similares, indicando que o tamanho efetivo da população é um parâmetro dos mais importantes no processo seletivo. Como mencionado anteriormente para o caso das perdas por fixação, um aumento no valor da razão sexual, que implicou no acasalamento de um único reprodutor com grande número de fêmeas, teve como conseqüência, um decréscimo na variabilidade genética da população, tanto em termos de alelos favoráveis e desfavoráveis e, por conseguinte, um decréscimo também no tempo total, no qual essa população conseguiria responder à seleção.

Segundo Falconer (1987), as respostas à seleção não são esperadas indefinidamente, visto que, depois de determinado número de gerações, todos os alelos favoráveis que estiverem segregando na população, tenderão a ser fixados. À medida que os alelos favoráveis se aproximarem da fixação, haverá paralelamente, redução na resposta para a seleção, de maneira que, ao cessar a resposta, afirma-se que a população está no seu limite da seleção.

Decréscimos mais acentuados nos valores do limite da seleção em populações com tamanho efetivo menor também foram relatados por Eisen (1980), a partir de um estudo com ratos, em programas de seleção a longo prazo. Segundo esse autor, à medida que o tamanho efetivo da população aumenta, é possível prolongar o tempo de resposta da população à seleção, em termos do número de gerações necessárias para esgotar seu potencial genético, bem como obter respostas que sejam otimizadas.

\section{CONCLUSÕES}

Tipos de acasalamento com restrição aos acasalamentos entre indivíduos aparentados possibilitam a manutenção da variabilidade genética por maior número de gerações e, portanto, asseguram mais tempo de resposta à seleção, quando praticados em população de tamanho efetivo acima de 36,36, valor máximo no caso deste estudo.

\section{REFERÊNCIAS BIBLIOGRÁFICAS}

BIJMA, P.; WOOLLIAMS, J.A. Prediction of rates of inbreeding in populations selected on best linear unbiased prediction of breeding value. Genetics, v.156, p.361-373, 2000 .

CABALLERO, A. Developments in the prediction of effective population size. Heredity, v.73, p.657-679, 1994.

EISEN, J. Conclusions from long-term selection experiments with mice. J. Ser. N.C. Agric. Res. Serv., p.305-319, 1980

EUCLYDES, R.F. Uso do sistema para simulação Genesys na avaliação de métodos de seleção clássicos e associados a marcadores moleculares. 1996. 149f. Tese (Doutorado em Genética e Melhoramento). Universidade Federal de Viçosa, Viçosa, MG.

FALCONER, D.S. Introdução à genética quantitativa. Viçosa, MG: UFV, 1987.279p.

KELLER, D.S.; GEARHEART, W.W.; SMITH, C.A comparison of factors reducing selection response in closed nucleus breeding schemes. J. Anim. Sci., v.68, p.1553-1561, 1990.

MEUWISSEN, T.H.E. Maximizing the response of selection with a predefined rate of inbreeding. J. Anim. Sci., v.75, p.934-940, 1997.

MEUWISSEN, T.H.E.; WOOLLIAMS, J.A. Effective sizes of livestock populations to prevent a decline in fitness. Theor. Appl. Genet., v.89, p.1019-1026, 1994.

NICHOLAS, F.W.; SMITH, C. Increased rates of genetic change in dairy cattle by embryo transfer and splitting. Anim. Prod., v.36, p.341-353, 1983.

SANCHEZ, L.; TORO, M.A.; GARCIA, C. Improving the efficiency of artificial selection: more selection pressure with less inbreeding. Genetics, v.151, p.1103-1114, 1999.

SANTIAGO, E.; CABALLERO, A. Effective size of populations under selection. Genetics, v. 139, p. 1013-1030, 1995.

SHIMBO, M.V.; FERRAZ, J.B.S.; ELER, J.P. et al. Influência da endogamia sobre características de desempenho em bovinos da raça Nelore. In: SIMPÓSIO NACIONAL DA SOCIEDADE BRASILEIRA DE MELHORAMENTO ANIMAL, 3., 2000, Belo Horizonte, MG. Anais... Belo Horizonte, 2000. p.388-390.

TORO, M.A.; NIETO, B.; SALGADO, C. A note on minimization of inbreeding in small-scale selection programmes. Livest. Prod. Sci., v.20, p.317-323, 1988.

TORO, M.A.; PEREZ-ENCISO, M. Optimization of selection response under restricted inbreeding. Genet. Select. Evol., v.22, p.93-107, 1990.

WOOLLIAMS, J.A. Modifications to MOET nucleus breeding schemes to improve rates of genetic progress and decrease rates of inbreeding in dairy cattle. Anim. Prod., v.49, p.1-14, 1989. 